\title{
Crack constitutive model for the prediction of punching failure modes of fiber reinforced concrete laminar structures
}

\author{
A. Ventura-Gouveia ${ }^{1 *}$, Joaquim A. O. Barros ${ }^{2 a}$, Álvaro F. M. Azevedo ${ }^{3 b}$ \\ ${ }^{I}$ Dept. of Civil Eng., ISISE, School of Technology \& Management, Polytechnic Institute of Viseu, Viseu, Portugal \\ ${ }^{2}$ Dept. of Civil Eng., ISISE, School of Engineering, University of Minho, Guimarães, Portugal \\ ${ }^{3}$ Dept. of Civil Eng., Faculty of Engineering of the University of Porto, University of Porto, Porto, Portugal
}

\begin{abstract}
The capability of a multi-directional fixed smeared crack constitutive model to simulate the flexural/punching failure modes of fiber reinforced concrete (FRC) laminar structures is discussed. The constitutive model is implemented in a computer program based on the finite element method, where the FRC laminar structures were simulated according to the Reissner-Mindlin shell theory. The shell is discretized into layers for the simulation of the membrane, bending and out-of-plane shear nonlinear behavior. A stress-strain softening diagram is proposed to reproduce, after crack initiation, the evolution of the normal crack component. The in-plane shear crack component is obtained using the concept of shear retention factor, defined by a crack-strain dependent law. To capture the punching failure mode, a softening diagram is proposed to simulate the decrease of the out-of-plane shear stress components with the increase of the corresponding shear strain components, after crack initiation. With this relatively simple approach, accurate predictions of the behavior of FRC structures failing in bending and in shear can be obtained. To assess the predictive performance of the model, a punching experimental test of a module of a façade panel fabricated with steel fiber reinforced self-compacting concrete is numerically simulated. The influence of some parameters defining the softening diagrams is discussed.
\end{abstract}

Keywords: Smeared Crack Model; Punching; Shear Softening Diagram; Material Nonlinear Analysis; Steel Fiber Reinforced Self-Compacting Concrete; Inverse Analysis.

\footnotetext{
* Corresponding Author, MSc, PhD Student, E-mail: ventura@estv.ipv.pt

${ }^{a}$ Associate Professor, Aggregation, E-mail: barros@ civil.uminho.pt

${ }^{\mathrm{b}}$ Assistant Professor, PhD, E-mail: alvaro@fe.up.pt
} 


\section{Introduction}

The Reissner-Mindlin theory for shell structures is commonly used to predict the behavior of laminar concrete structures up to failure (Barros and Figueiras 2001). The thickness of the laminar structure is discretized in layers that are assumed subjected to a plane stress state. The use of laws to simulate the nonlinear behavior, after crack initiation, for the in-plane fracture modes is appropriate in most cases, and the deformational response of the structure for load configurations inducing flexural failure modes can be predicted with sufficient accuracy. However, the simulation of laminar structures failing in punching is a much more complex task, being the treatment of the out-of-plane shear components of paramount importance. In the present work, in order to explore the use of a simple approach to simulate the material nonlinear behavior of concrete laminar structures failing in punching, a softening law is proposed to model both out-of-plane shear components. This crack constitutive model has been implemented in the FEMIX computer program, which is based on the finite element method (Sena-Cruz et al. 2007). Since the shell model only admits cracks that are orthogonal to its middle surface, the inclined cracks that are observed in the experimental punching tests cannot be accurately predicted. For this purpose a much more complex and time-consuming general 3D crack constitutive model must be used (Barzegar and Maddipudi 1997).

Steel fiber reinforced self-compacting concrete (SFRSCC) is a relatively recent cement-based material that combines the benefits of the self-compacting concrete technology (Okamura 1997) with the advantages of the addition of fibers to a brittle cementitious matrix (Pereira 2006). The developed SFRSCC was used to manufacture the lightweight panel system schematically represented in Fig. 1, which can be applied in building façades (Barros et al. 2005a). The mix composition of the SFRSCC used to manufacture the panel is presented in Table 1. In the composition of the SFRSCC, $30 \mathrm{~kg} / \mathrm{m}^{3}$ of hooked ends steel fibers with a length $\left(l_{f}\right)$ of $60 \mathrm{~mm}$, a diameter $\left(d_{f}\right)$ of $0.75 \mathrm{~mm}$, an aspect ratio $\left(l_{f} / d_{f}\right)$ of 80 and a yield stress of $1100 \mathrm{MPa}$ were used. At seven days the average value of the compressive strength and modulus of elasticity of this SFRSCC was $52 \mathrm{MPa}$ and $31 \mathrm{GPa}$, respectively. The flexural strength of this type of structural elements is a key aspect in their design, since, in general, the bending moments of the 
wind load combination are an important factor in the design process of the panel. To assess the panel flexural behavior, representative modules of the SFRSCC panel system were tested, being the details of the experimental program described elsewhere (Barros et al. 2007). The punching resistance is also a key aspect in the design of this type of panel, since its lightweight zones consist of a thin layer that is only $30 \mathrm{~mm}$ thick. To evaluate the punching resistance of these zones, representative modules of the panel system are submitted to a load configuration that implies the occurrence of this type of failure mode (Barros et al. 2005a, Barros et al. 2007). The results obtained in one of these tests were compared with the numerical simulations in order to assess the predictive performance of the developed model. Several numerical simulations are carried out to assess the influence of some parameters that define the softening diagrams. The objective of these simulations is to understand how each parameter affects the response of a laminar FRC structure failing in punching. The influence of the in-plane mesh and through-thickness refinement of the simulated structure is also analyzed.

The possibility of defining the fracture parameters that characterize the fracture mode I strain-softening diagram by performing an inverse analysis (IA) (Barros et al. 2005b) is also discussed. The IA is based on the results obtained in three point notched beam bending tests carried out according to the RILEM TC 162-TDF recommendations (Vandewalle et al. 2002).

\section{Crack constitutive model}

\section{1 - Introduction}

Presently, several finite element approaches are available to analyze the behavior of complex structures subject to arbitrary loads. The most recent ones are capable of modeling the behavior of concrete structures presenting brittle failure modes, and accurately predict crack formation and progression. Discrete cohesive fracture models (discrete) with fragmentation algorithms, strong discontinuity approaches (continuum) with the embedded discontinuities method and the extended finite element method are examples of advanced methodologies that, together with powerful mesh refinement algorithms, reveal great efficiency in modeling the concrete fracture initiation and propagation (Yu et al. 2007). Alternative methods are based on damage models 
(de Borst and Gutiérrez 1999), smeared crack models (Bazant and Oh 1983)] and microplane models (Bazant 1984). These methods are less precise to predict the local phenomena related to crack propagation, but from the computational effectiveness and the assessment of the global behavior of a concrete structure point-of-views, are more appropriate to analyze complex structures with a large number of degrees of freedom. As shown by de Borst (2002), "fixed and rotating smeared crack models, but also microplane models, can be conceived as a special case of (anisotropic) damage models", these three FEM-based solutions are closely related and produce similar results. Taking into account the main characteristics of all these approaches, the multi-directional fixed smeared crack model was selected and implemented in the scope of the present research, since it allows for the analysis of large scale SFRSCC structures (de Borst 1987, Rots 1988, Dahlblom and Ottosen 1990), as long as an appropriate constitutive law is used to model the SFRSCC post-cracking behavior.

\section{2 - Formulation}

In the context of finite element material nonlinear behavior of concrete shell structures, the developed crack constitutive model is implemented under the framework of the Reissner-Mindlin theory adapted to the case of layered shells. The description of the formulation is restricted to the case of cracked concrete, for a selected concrete layer, and at the domain of an integration point $(I P)$ of a finite element. According to the adopted constitutive law, stresses and strains are related by the following equation

$$
\left[\begin{array}{c}
\Delta \underline{\boldsymbol{\sigma}}_{m f} \\
\underline{\boldsymbol{\sigma}}_{s}
\end{array}\right]=\left[\begin{array}{cc}
\underline{D}_{m f}^{c r c o} & \underline{0} \\
\underline{0} & \underline{D}_{s}^{c r c o}
\end{array}\right]\left[\begin{array}{c}
\Delta \underline{\boldsymbol{\varepsilon}}_{m f} \\
\underline{\boldsymbol{\varepsilon}}_{s}
\end{array}\right]
$$

where $\Delta \underline{\sigma}_{m f}=\left\{\Delta \sigma_{1}, \Delta \sigma_{2}, \Delta \tau_{12}\right\}^{T}$ and $\Delta \underline{\varepsilon}_{m f}=\left\{\Delta \varepsilon_{1}, \Delta \varepsilon_{2}, \Delta \gamma_{12}\right\}^{T}$ are the vectors of the incremental stress and incremental strain in-plane components, while $\underline{\sigma}_{s}=\left\{\tau_{23}, \tau_{31}\right\}^{T}$ and $\underline{\varepsilon}_{s}=\left\{\gamma_{23}, \gamma_{31}\right\}^{T}$ are the vectors of the total stress and total out-of-plane shear strain components. 
Due to the decomposition of the total strain into an elastic concrete part and a crack part $\left(\varepsilon^{c r c o}=\mathcal{E}^{c o}+\mathcal{\varepsilon}^{c r}\right.$ ), in Eq. (1) the in-plane cracked concrete constitutive matrix, $\underline{D}_{m f}^{c r c o}$, is obtained with the following equation (Sena-Cruz 2004)

$$
\underline{D}_{m f}^{c r o s}=\underline{D}_{m f, e}^{c o}-\underline{D}_{m f, e}^{c o}\left[\underline{T}^{c r}\right]^{T}\left(\underline{D}^{c r}+\underline{T}^{c r} \underline{D}_{m f, e}^{c o}\left[\underline{T}^{c r}\right]^{T}\right)^{-1} \underline{T}^{c r} \underline{D}_{m f, e}^{c o}
$$

where $\underline{D}_{m f, e}^{c o}$ is the constitutive matrix of concrete with a linear and elastic behavior

$$
\underline{D}_{m f, e}^{c o}=\frac{E}{1-v^{2}}\left[\begin{array}{ccc}
1 & v & 0 \\
v & 1 & 0 \\
0 & 0 & (1-v) / 2
\end{array}\right]
$$

where $E$ and $v$ are the elasticity modulus and the Poisson's ratio of concrete, respectively. In Eq. (2), $\underline{T}^{c r}$ is the matrix that transforms the stress components from the coordinate system of the finite element to the local crack coordinate system

$$
\underline{T}^{c r}=\left[\begin{array}{ccc}
\cos ^{2} \theta & \sin ^{2} \theta & 2 \sin \theta \cos \theta \\
-\sin \theta \cos \theta & \sin \theta \cos \theta & \cos ^{2} \theta-\sin ^{2} \theta
\end{array}\right]
$$

and $\underline{D}^{c r}$ is the crack constitutive matrix

$$
\underline{D}^{c r}=\left[\begin{array}{cc}
D_{I}^{c r} & 0 \\
0 & D_{I I}^{c r}
\end{array}\right]
$$

In Eq. (4), $\theta$ is the angle between $x_{I}$ and $n$ (see Fig. 2). In Eq. (5), $D_{I}^{c r}$ and $D_{I I}^{c r}$ represent, respectively, the constitutive components relative to the crack opening mode I (normal) and mode II (in-plane shear).

The crack opening propagation is simulated with the trilinear diagram represented in Fig. 3, which is defined by the parameters $\alpha_{i}$ and $\xi_{i}$, relating stress with strain at the transitions between the linear segments that compose this diagram. The ultimate crack strain, $\varepsilon_{n, u}^{c r}$, is defined as a function of the parameters $\alpha_{i}$ and $\xi_{i}$, the fracture energy, $G_{f}^{I}$, the tensile strength, $f_{c t}=\sigma_{n, 1}^{c r}$, and the crack bandwidth, $l_{b}$, as follows (Sena-Cruz 2004),

$$
\varepsilon_{n, u}^{c r}=\frac{2}{\xi_{1}+\alpha_{1} \xi_{2}-\alpha_{2} \xi_{1}+\alpha_{2}} \frac{G_{f}^{I}}{f_{c t} l_{b}}
$$


where $\alpha_{1}=\sigma_{n, 2}^{c r} / \sigma_{n, 1}^{c r}, \alpha_{2}=\sigma_{n, 3}^{c r} / \sigma_{n, 1}^{c r}, \xi_{1}=\varepsilon_{n, 2}^{c r} / \varepsilon_{n, u}^{c r}$ and $\xi_{2}=\varepsilon_{n, 3}^{c r} / \varepsilon_{n, u}^{c r}$.

The fracture mode II modulus, $D_{I I}^{c r}$, is obtained with

$$
D_{I I}^{c r}=\frac{\beta}{1-\beta} G_{c}
$$

where $G_{c}$ is the concrete elastic shear modulus and $\beta$ is the shear retention factor. The parameter $\beta$ is defined as a constant value or as a function of the current crack normal strain, $\mathcal{E}_{n}^{c r}$, and of the ultimate crack normal strain, $\varepsilon_{n, u}^{c r}$, as follows,

$$
\beta=\left(1-\frac{\varepsilon_{n}^{c r}}{\varepsilon_{n, u}^{c r}}\right)^{p_{1}}
$$

When $p_{1}$ is unitary, a linear decrease of $\beta$ with the increase of $\mathcal{E}_{n}^{c r}$ is assumed. Larger values of the exponent $p_{1}$ correspond to a more pronounced decrease of the parameter $\beta$, in order to simulate a higher in-plane shear stress degradation with the crack opening process (Barros et al. 2004). A softening constitutive law to model the in-plane crack shear stress transfer has also been implemented in the FEMIX code, but its adoption as an alternative to the shear retention concept does not contribute to an increase of the accuracy of the numerical simulations, and causes difficulties in the convergence of the Newton-Raphson procedure.

The definition of the out-of-plane $(O P)$ constitutive matrix, $\underline{D}_{s}^{\text {crco }}$ in Eq. (1), is based on the diagram represented in Fig. 4. When the concrete associated with the IP changes from uncracked to cracked state, the out-of-plane shear stresses are stored for later use and each out-of-plane shear stress-strain relation $\left(\tau_{23}-\gamma_{23}\right.$ and $\left.\tau_{31}-\gamma_{31}\right)$ follows the softening law depicted in Fig. 4. Therefore, the $\underline{D}_{s}^{\text {crco }}$ matrix is defined by

$$
\underline{D}_{s}^{c r c o}=\left[\begin{array}{cc}
D_{I I I, \mathrm{sec}}^{23} & 0 \\
0 & D_{I I I, \mathrm{sec}}^{31}
\end{array}\right]
$$

where

$$
D_{I I I, \mathrm{sec}}^{23}=\frac{\tau_{23, \max }^{O P}}{\gamma_{23, \max }^{O P}}, \quad D_{I I I, \mathrm{sec}}^{31}=\frac{\tau_{31, \max }^{O P}}{\gamma_{31, \max }^{O P}}
$$


in accordance with the secant approach shown in Fig. 4. Each peak shear strain is calculated using the stored peak shear stress at crack initiation and $G_{c}$

$$
\gamma_{23, p}^{O P}=\frac{\tau_{23, p}^{O P}}{G_{c}}, \quad \gamma_{31, p}^{O P}=\frac{\tau_{31, p}^{O P}}{G_{c}}
$$

Each out-of-plane ultimate shear strain, $\gamma_{u}^{O P}$, is defined as a function of the out-of-plane peak shear strain, $\gamma_{p}^{O P}$, the out-of-plane shear strength, $\tau_{p}^{O P}$, the mode III (out-of-plane) fracture energy, $G_{f}^{I I I}$, and the crack bandwidth, $l_{b}$, as follows

$$
\gamma_{23, u}^{O P}=\gamma_{23, p}^{O P}+\frac{2 G_{f}^{I I I}}{\tau_{23, p}^{O P} l_{b}}, \quad \gamma_{31, u}^{O P}=\gamma_{31, p}^{O P}+\frac{2 G_{f}^{I I I}}{\tau_{31, p}^{O P} l_{b}}
$$

The present approach assumes that the crack bandwidth used to assure mesh independence when modeling fracture mode I can also be adopted in the out-of-plane fracture process.

\section{Evaluation of the mode I fracture properties by inverse analysis}

This section describes the inverse analysis (IA) methodology adopted to evaluate the fracture mode I parameters of the SFRSCC used in the panel prototype that was experimentally tested and numerically simulated. Detailed information about this IA can be found elsewhere (Barros et al. 2005b, Sena-Cruz et al. 2004).

As already mentioned, in the implemented smeared crack constitutive model the post-cracking behavior of SFRSCC under tension is described by a trilinear stress-strain softening diagram

(Fig. 3). This function is defined by a set of fracture parameters $\left(\alpha_{i}, \xi_{i}, G_{f}^{I}, f_{c t}\right.$ and $\left.l_{b}\right)$, being the accuracy of the FEM modeling largely dependent on the values that are assigned to these parameters. In this context, the experimental behavior of an element failed in bending may be predicted by a FEM model, as long as the correct values of the material fracture parameters are introduced in the constitutive model. The adopted strategy consists in the evaluation of the $\xi_{i}$, $\alpha_{i}$ and $G_{f}^{I}$ parameters that define the shape of the trilinear $\sigma_{n}^{c r}-\varepsilon_{n}^{c r}$ constitutive law, based on the minimization of the error parameter 


$$
e r r=\left|A_{F-\delta}^{\exp }-A_{F-\delta}^{\text {num }}\right| / A_{F-\delta}^{\exp }
$$

where $A_{F-\delta}^{\text {exp }}$ and $A_{F-\delta}^{\text {num }}$ are the areas beneath the experimental and numerical load-deflection curves corresponding to a three point notched beam bending test (Sena-Cruz et al. 2004). The experimental curve corresponds to the average results observed in prismatic SFRSCC notched specimens, tested according to the RILEM TC 162-TDF recommendations at the age of 7 days (Vandewalle et al. 2002), while the numerical curve consists of the results obtained by FEM analysis, where the specimen, loading and support conditions are simulated in agreement with the experimental flexural test setup (Fig. 5a). In this context, the specimen is modeled with a mesh of 8 node serendipity plane stress finite elements. The Gauss-Legendre integration scheme with $2 \times 2$ integration points is used in all elements, with the exception of the elements at the specimen symmetry axis, where $1 \times 2$ integration points are used. With this particular integration point layout, the numerical results have a better agreement with the experimental observations, since a vertical crack may develop along the symmetry axis. Linear elastic material behavior is assumed in all the elements, with the exception of those above the notch, along the symmetry axis. In this region an elastic-cracked material model in tension is adopted. The crack bandwidth, $l_{b}$, is assumed to be equal to $5 \mathrm{~mm}$, being this value coincident with the width of the notch and of the elements located above it.

In Fig. 5b, the results experimentally obtained in the flexural tests are compared with the numerical results. The curve of the numerical simulation, obtained with the optimized fracture parameters, is not perfectly coincident with the experimental curve, suggesting that more parameters should be considered in order to obtain a better fitting. The values of the fracture parameters $\xi_{i}, \alpha_{i}$ and $G_{f}^{I}$ that lead to the numerical results represented in Fig. 5b are listed in Table 2. 


\section{Numerical simulation}

\section{1 - Introduction}

The punching test of a module of the developed SFRSCC lightweight panel is used to assess the predictive performance of the proposed multi-directional fixed smeared crack model. The test layout and the test setup are represented in Fig. 6. More details about the corresponding experimental program can be found elsewhere (Barros et al. 2007).

The influence of mesh refinement and some model parameters in the results of the numerical simulations is assessed and discussed in this section, namely: the values adopted for the fracture mode I parameters used to define the trilinear diagram and the values used to define the out-ofplane shear stress-strain diagram.

\section{2 - Analysis based on the values obtained from the IA.}

\subsection{1 - Influence of the out-of-plane shear softening diagram}

The results of the numerical simulations are compared with the experimental data obtained in the punching test of the panel module. The finite element idealization, load and support conditions used in the numerical simulations of the punching test are shown in Fig. 7a. Only one quarter of the panel is used in the simulations, due to double symmetry. The mesh is composed of $6 \times 6$ eight-node serendipity plane shell elements. The elements are divided into 11 layers, each one being $10 \mathrm{~mm}$ thick. Since the panel has lightweight zones (shaded elements in Fig. 7a), materialized by the suppression of $80 \mathrm{~mm}$ of concrete in the central zone, null stiffness is assigned to the 8 bottom layers of the corresponding finite elements (see Fig 7b). The material of the remaining three layers has an elastic-cracked behavior, as described in Section 2.2. This model is also used in the elements located outside the central lightweight zone.

A trial-and-error procedure is required to estimate reasonable values for the out-of-plane components of the elastic-cracked constitutive matrix, $\underline{D}_{s}^{\text {crco }}$, since their experimental evaluation is quite complex and beyond the scope of the present work. The out-of-plane shear fracture energy that leads to the best agreement with the experimental results of the punching tests, 
$G_{f}^{I I I}=3.0 \mathrm{~N} / \mathrm{mm}$, is determined with this procedure. The values of the mode I fracture parameters that take part in the in-plane elastic-cracked constitutive matrix for concrete, $\underline{D}_{m f}^{\text {crco }}$, are obtained by IA, as described in Section 3. In Fig. 8 the responses obtained with the numerical model are compared with the experimental results. A good agreement can be observed up to a deflection of $2.5 \mathrm{~mm}$. For larger deflections, an overestimation of the load carrying capacity of the prototype panel occurs when a linear elastic behavior is assumed for the out-of-plane shear components. At a deflection of about $3 \mathrm{~mm}$ the experimental curve suddenly falls, indicating the failure of the panel by punching, as visually confirmed in the experimental test. This load decay that is not reproduced when assuming a linear elastic behavior for the out-of-plane shear components is, however, well captured when the bilinear diagram represented in Fig. 4 is used to model the softening behavior of the out-of-plane shear components, with $G_{f}^{I I I}=3.0 \mathrm{~N} / \mathrm{mm}$, and assuming a crack bandwidth, $l_{b}$, equal to the square root of the area associated with the corresponding IP. The abrupt load decay from approximately $41 \mathrm{kN}$ to $20 \mathrm{kN}$, which is observed in the experimental test, is accurately simulated by the numerical model, as well as the subsequent extended stage of residual load carrying capacity exhibiting a very small load decay.

Up to a $10 \mathrm{kN}$ load all the curves depicted in Fig. 8 are practically coincident. Afterwards, the straight line that represents the response assuming a linear-elastic behavior no longer follows the curves that correspond to the experimental test and to the numerical analysis with material nonlinear model. These results suggest that some cracks start to form at a very early stage of the experimental test. The nonlinear numerical model accurately captures the formation of bending cracks at the top surface (see Fig. 9a), in agreement with the experimentally observed crack pattern. Fig. $9 \mathrm{~b}$ shows the crack pattern at the top surface observed at the end of the test sequence. The numerical model also indicates the formation of bending cracks at the bottom surface, in the lightweight zone. These cracks initiate at the center of the panel, beneath the loaded area, and then progress to the corners of the lightweight zone, showing some similarities 
with the classical yield lines formed in square concrete slabs failing by flexure. These cracks can also be observed in the experimental test (Pereira 2006).

In conclusion, the results indicate that flexure mechanisms prevail in the deformational behavior up to a deflection of approximately $2.5 \mathrm{~mm}$. For larger deflections, the punching failure mechanisms start to assume a greater relevance, and the overestimation of the panel out-of-plane rigidity components, when linear out-of-plane shear behavior is assumed, leads to a divergence between the numerical model and the experimental observations. With the adoption of a softening law for the out-of-plane shear components, the numerical model becomes much more accurate in the prediction of the complete behavior of the panel failing in punching, capturing the sudden load decay associated with punching failure mechanisms.

As already mentioned, the selection of a value for $G_{f}^{I I I}$ has no experimental support. In order to analyze its influence on the results of the numerical simulation using a softening law for both out-of-plane components, a parametric analysis is carried out consisting in the variation of its value from 1.0 to $5.0 \mathrm{~N} / \mathrm{mm}$. The results depicted in Fig. 10 show that a value of $G_{f}^{I I I}=3.0 \mathrm{~N} / \mathrm{mm}$ leads to a perfect prediction of the abrupt load decay experimentally observed at a deflection of about $3 \mathrm{~mm}$. Increasing or decreasing the value of $G_{f}^{I I I}$ implies the occurrence of the abrupt load decay at a larger or smaller deflection, respectively. The conclusion of this study is that, independently of the value of $G_{f}^{I I I}$, when using the model described in this work, it is essential to use a softening law for the out-of-plane shear components in order to simulate the sudden load decay observed in the punching test.

\subsection{2 - Influence of the through-thickness refinement of the panel}

In this section, the influence of through-thickness refinement of the panel on the load-deflection relationship is analyzed. The parameters used to simulate the fracture mode I and the out-ofplane shear softening diagram are those that have best fitted the experimental results, according to the strategy described in the previous section. 
For this purpose, the following two refinements are considered: 6 layers in the lightweight zone and 22 layers in the remaining parts; 10 layers in the lightweight zone and 26 layers in the other zones.

In Fig. 11 the load-deflection relationships of these numerical simulations are compared with the experimental one. In the legend of this figure, $C_{-} \_j L$ represents the relationship obtained from the simulation whose lightweight zone was discretized in $j$ layers. It can be observed that by increasing the number of layers from 3 to 6 in the lightweight zone, the maximum load increases in about $17 \%$ and the stiffness corresponding to the branch between crack initiation and peak load also increases. This behavior can be justified by the fact that the flexural stiffness of the layers is not taken into account in the layered approach adopted to simulate the stiffness of Mindlin shell finite elements, when a material nonlinear analysis is performed. Therefore, the larger the number of layers discretizing the element, the higher the flexural stiffness of the element is, resulting in a smaller deformability of the panel and a higher load carrying capacity. However, Fig. 11 also shows that when the number of layers increases from 6 to 10 , only a marginal increase of the maximum load is visible, which indicates that the increase ratio of the flexural stiffness and load carrying capacity of the layered Mindlin-shell element decreases with the number of layers.

It is also interesting to observe that the deflection at the abrupt load decay, as well as the residual load carrying capacity of the panel are very similar in all three numerical analysis.

\subsubsection{Influence of the in-plane mesh refinement of the panel}

In order to assess the influence of the in-plane mesh refinement on the load-deflection relationship, an analysis with the refined mesh (RM) represented in Fig. 12 is carried out. Eight-node serendipity plane shell elements are used, with 10 layers in the lightweight zone and 26 layers in the other zones.

The load-deflection relationship for the RM is represented in Fig. 13, which is compared with the one obtained with the previous coarse mesh $(\mathrm{CM})$, and with the one experimentally registered. As expected, the deformability of the panel increases with the mesh refinement, 
causing the abrupt load decay to occur for a higher deflection $(3.3 \mathrm{~mm})$. Due to the higher flexibility of the panel when performing the analysis with the RM, a decrease of about $5 \%$ in terms of load carrying capacity occurs. Therefore, the shape of the load-deflection $(F-u)$ curve for the $\mathrm{RM}$ is approximately the result of the rotation of the $F-u$ curve for the $\mathrm{CM}$ in turn of the point that corresponds to the crack initiation.

With the increase of the number of finite elements (and number of integration points), the concrete in cracked status and the corresponding consumed mode I fracture energy also increase. This can be a possible justification for this more deformable response of the in-plane RM numerical simulation.

\subsubsection{Influence of the fracture energy $\left(G_{f}^{I I I}\right)$ used in the out-of-plane shear softening diagram}

To assess the influence of the fracture energy used to define the out-of-plane shear softening diagram, $G_{f}^{I I I}$, on the load-deflection relationship, its value is varied between $1.0 \mathrm{~N} / \mathrm{mm}$ and 5.0 N/mm. In these analyses the in-plane CM and the RM are used, with 10 layers discretizing the thickness of the panel in the lightweight zone. The obtained numerical curves are represented in Fig. 14a and 14b, respectively. It is observed that in the RM the $G_{f}^{I I I}$ value mainly affects the residual load carrying capacity after the abrupt load decay. When using the $\mathrm{CM}$, the value attributed to $G_{f}^{I I I}$ not only affects the residual load carrying capacity but also influences the value of the deflection corresponding to the abrupt load decay. This influence, however, is less pronounced than when using an in-plane CM with 3 layers discretizing the thickness of the panel in the lightweight zone (see Fig. 10). Therefore it can be concluded that when a RM is used, suitable predictions can be obtained with $G_{f}^{I I I}=G_{f}^{I}$, but further research needs to be carried out for a more reliable estimation of $G_{f}^{I I I}$.

Figures $15 \mathrm{a}$ and $15 \mathrm{~b}$ show the consumed out-of-plane fracture energy $\left(G_{f, c}^{I I I}\right)$ up to a deflection of $3.5 \mathrm{~mm}$ for the in-plane $\mathrm{CM}$ and $\mathrm{RM}$, respectively. In each integration point, this consumed fracture energy receives the contribution of the two out-of-plane shear components in all layers 
discretizing the thickness of the panel, and can be regarded as an indicator of damaged due to punching failure mode. It can be observed that the punching failure pattern is well predicted when using the RM. When using the in-plane CM refinement the shear failure bandwidth is larger, which justifies the higher sensitivity of the deflection corresponding to the abrupt load decay to the adopted $G_{f}^{I I I}$ value (Figure 14a).

\section{3 - Influence of the parameters that define the fracture mode I}

In order to assess the influence of the parameters that define the fracture mode I constitutive law (Fig. 3) on the load-deflection relationship predicted by the numerical model, the values of these parameters are decreased and increased by $50 \%$ relatively to those obtained by IA. The crack stress vs. crack strain $\left(\sigma_{n}^{c r}-\varepsilon_{n}^{c r}\right)$ for these analyses and the corresponding load-deflection relationships are depicted in Figs. 16 to 20 . All these numerical analyses were performed with the refined mesh and using 10 layers for the discretization of the thickness of the lightweight part of the panel. From the analysis of these graphs it can be concluded that the inclination of the first branch of the $\sigma_{n}^{c r}-\varepsilon_{n}^{c r}$ diagram ( $D_{n 1}^{c r}$ in Fig. 3) governs the point corresponding to the first drop in the load-deflection relationship. In fact, the less abrupt is this branch the higher is the load of this point. In consequence, the load carrying capacity of the panel is quite sensible to the slope of this branch. Direct tensile tests with SFRSCC similar to the one used in the tested panels showed, in fact, an abrupt stress decay immediately after crack formation. Fig. 17b evidences that the numerically predicted load carrying capacity of the panel is quite dependent on the $\alpha_{1}$ parameter, since a pronounced softening and a significant hardening deflection are estimated when a value of $\alpha_{1}$ smaller or larger than the one obtained by IA is used (Fig. 17a). The higher strength $\sigma_{n}^{c r}\left(\varepsilon_{n}^{c r}\right)$ of the second branch of $\sigma_{n}^{c r}-\varepsilon_{n}^{c r}$, when adopting higher values for the $\alpha_{1}$ parameter (Fig. 17a), also contributes to increase both the load carrying capacity of the panel and the deflection corresponding to the punching failure. However, Fig. 19 reveals that

the strength $\sigma_{n}^{c r}\left(\varepsilon_{n}^{c r}\right)$ corresponding to the first branch of $\sigma_{n}^{c r}-\varepsilon_{n}^{c r}$ diagram has a much higher 
influence on the load carrying capacity of the panel than the strength $\sigma_{n}^{c r}\left(\varepsilon_{n}^{c r}\right)$ of the second branch. Nevertheless, Fig. 19 and Fig. 20 also demonstrate that the slope of the load-deflection branch before the punching failure grows with the value of $D_{n 2}^{c r}$ (Fig. 3). Finally, the decrease of the fracture energy is mainly reflected on the point corresponding to the first drop of the loaddeflection relationship (Fig. 20b). This decrease lead to a more abrupt decay of the first branch of the $\sigma_{n}^{c r}-\varepsilon_{n}^{c r}$ diagram (Fig. 20a), resulting a decrease of the load at this point

\section{Conclusions}

In the present work a model based on the finite element method is proposed to simulate fiber reinforced concrete (FRC) structures failing in bending and shear. The Reissner-Mindlin theory, in the context of layered shells, is selected and special emphasis is dedicated to the treatment of the shear behavior. The model is based on a multi-directional fixed smeared crack concept. By considering the nonlinear behavior of each shell layer, crack propagation through the thickness of these structures can be simulated. Fracture mode I is modeled with a crack stress $v s$. crack strain trilinear diagram, whose defining parameters can be obtained by inverse analysis (IA) using the load-deflection relationship obtained with three-point notched beam tests, carried out according to the RILEM TC 162-TDF recommendations. With this strategy the values of the fracture parameters that define the normal stress-strain crack constitutive relationship are obtained. Since this type of test is much simpler and faster to execute, it becomes an advantageous alternative to the direct tensile tests recommended to evaluate the fracture mode I parameters of cement based materials. The adopted IA strategy is presented and discussed in the numerical simulation section. To simulate the out-of-plane strain gradient that occurs in punching tests, a softening diagram is proposed to model, after crack initiation, the out-of-plane shear components. The adequacy and accuracy of the model is appraised using the results obtained in the punching test of a panel prototype built with steel fiber reinforced self-compacting concrete (SFRSCC). This numerical strategy allows for an accurate simulation of the load-deformational process of the experimentally tested panel, which exhibited a brittle punching failure. 
Several numerical simulations are presented and discussed. Mesh refinement, data obtained with inverse analysis to define the trilinear diagram and a softening out-of-plane shear diagram are alternatives whose influence on the prediction of the experimental panel response is investigated. The use of softening laws to simulate the mode I crack opening and the out-of-plane shear components is crucial in order to obtain accurate numerical simulations The numerical simulations carried out with the proposed model and its comparison with the results of the experimental test used in this work lead to the conclusion that the behavior of laminar SFRSCC structures failing in punching can be numerically predicted by a FEM-based Reissner-Mindlin shell approach as long as a crack constitutive model that includes a softening diagram for modeling both out-of-plane shear constitutive laws is used. 


\section{ACKNOWLEDGEMENTS}

The authors wish to acknowledge the support provided by the Portuguese Science and Technology Foundation (FCT) by means of the project PTDC/ECM/73099/2006 "CUTINEMO - Carbon fiber laminates applied according to the near surface mounted technique to increase the flexural resistance to negative moments of continuous reinforced concrete structures". The first author acknowledges the financial support of FCT, PhD Grant number SFRH/BD/23326/2005.

\section{References}

Barros, J.A.O. and Figueiras, J.A. (2001), "Nonlinear analysis of steel fibre reinforced concrete slabs on grade", Computers \& Structures Journal, 79(1), 97-106, January.

Barros, J.A.O., Gettu, R. and Barragan, B.E. (2004), "Material Nonlinear analysis of Steel fibre reinforced concrete beams failing in shear", 6th International RILEM Symposium on fibre reinforced concrete - BEFIB 2004, Edts. M. di Prisco, R. Felicetti, G.A. Plizarri, Vol. 1, p. 711720, 20-22 September.

Barros, J.A.O., Pereira, E.N.B., Cunha, V.M.C.F., Ribeiro, A.F., Santos, S.P.F. and Queirós, P.A.A.A.V. (2005a), "PABERFIA - Lightweight sandwhich panels in steel fiber reinforced self compacting concrete", Technical Report 05-DEC/E-29, Dep. Civil Eng., School Eng. University of Minho, 63 pp, November.

Barros J.A.O., Cunha, V.M.C.F., Ribeiro, A.F. and Antunes, J.A.B. (2005b), "Post-cracking behaviour of steel fibre reinforced concrete”, RILEM Materials and Structures Journal, 38(275), $47-56$

Barros, J.A.O., Pereira, E.B. and Santos, S.P.F. (2007), "Lightweight panels of steel fiber reinforced self-compacting concrete", Journal of Materials in Civil Engineering, 19(4), 295-304. Barzegar, F. and Maddipudi, S. (1997), "Three-dimensional modeling of concrete structures. I: plain concrete", Journal of Structural Engineering, 123(10), 1339-1347. 
Bazant, Z.P. and Oh, B.H. (1983), "Crack band theory for fracture of concrete", Materials and Structures, RILEM, 16(93), 155-177.

Bazant, Z.P. (1984), “Microplane model for strain controlled inelastic behavior”, In: Desai, C.S., Gallagher, R.H. (Eds.), Mechanics of Engineering Materials. J. Wiley, London, pp. 5-59 (Chapter 3).

Dahlblom O. and Ottosen N.S. (1990), "Smeared crack analysis using generalized fictitious crack model", Journal of Engineering Mechanics, ASCE, 116(1), 55-76.

de Borst, R. (1987), "Smeared cracking, plasticity, creep and thermal loading - a unified approach", Computational Methods in Applied Mechanics Engineering, 62, 89-110.

de Borst, R. and Gutiérrez, M.A. (1999), "A unified framework for concrete damage and fracture models including size effects”, International Journal of Fracture, 95, 261-277.

de Borst, R. (2002), "Fracture in quasi-brittle materials: a review of continuum damage-based approaches”, Engineering Fracture Mechanics, 69, 95-112.

Okamura, H. (1997), "Ferguson Lecture for 1996: Self-compacting high-performance concrete", Concrete International, ACI 19(7), 50-4.

Pereira, E.N.B. (2006), "Steel fibre reinforced self-compacting concrete: from material to mechanical behavior", Dissertation for Pedagogical and Scientific Aptitude Proofs, Department of Civil Engineering, University of Minho, 188 pp, http://www.civil.uminho.pt/composites.

Rots, J.G. (1988), “Computational modeling of concrete fracture”, PhD Thesis, Delft University of Technology.

Sena-Cruz, J.M. (2004), "Strengthening of concrete structures with near-surface mounted CFRP laminate strips", $\mathrm{PhD}$ Thesis, Department of Civil Engineering, University of Minho, http://www.civil.uminho.pt/composites.

Sena-Cruz, J.M., Barros, J.A.O., Ribeiro, A.F., Azevedo, A.F.M. and Camões, A.F.F.L. (2004), "Stress-crack opening relationship of enhanced performance concrete", 9th Portuguese Conference on Fracture, ESTSetubal, Portugal, 395-403. 
Sena-Cruz, J.M., Barros, J.A.O., Azevedo, A.F.M. and Ventura-Gouveia, A. (2007), "Numerical simulation of the nonlinear behavior of RC beams strengthened with NSM CFRP strips", Proceedings of CMNE/CILAMCE Congress, FEUP, Porto, Portugal, 13-15 June.

Vandewalle, L. et al. (Technical Committee) (2002), "Test and design methods for steel fibre reinforced concrete - Final Recommendation", Materials and Structures, 35(253), 579-582.

Yu, R.C., Gonzalo, R. and Chaves, E.W.V. (2007), “A comparative study between discrete and continuum models to simulate concrete fracture", Engineering Fracture Mechanics, doi:10.1016/j.engfracmech.2007.03.031. 


\section{NOTATION}

$A_{F-\delta}^{\text {exp }}=$ areas beneath the experimental load-deflection curves

$A_{F-\delta}^{\text {num }}=$ areas beneath the numerical load-deflection curves

$d_{f}=$ steel fiber diameter

$\underline{D}^{c r}=$ crack constitutive matrix

$D_{n i}^{c r}=$ opening fracture mode stiffness modulus for the $i^{\text {th }}$ trilinear stress-strain softening branch

$D_{I}^{c r}=$ crack constitutive matrix component relative to the crack normal opening mode (mode I)

$D_{I I}^{c r}=$ crack constitutive matrix component relative to the crack inplane sliding mode (mode II)

$D_{I I, \text { sec }}^{i j}=$ secant constitutive matrix $i j$ component relative to the crack out-of-plane sliding mode (mode III)

$D_{I I I, \text { sec }}=$ secant stiffness relative to the crack out-of-plane sliding mode (mode III)

$\underline{D}_{m f, e}^{c o}=$ constitutive matrix of in-plane membrane and bending components for concrete in elastic regime

$\underline{D}_{m f}^{c r o s}=$ constitutive matrix of in-plane membrane and bending components for cracked concrete

$D_{s}^{\text {cro }}=$ constitutive matrix of out-of-plane shear components for cracked concrete

$E_{c}, E=$ concrete elasticity modulus

$\mathrm{FRC}=$ fiber reinforced concrete

$G_{c}=$ concrete elastic shear modulus

$G_{f}^{I}=$ mode I (in-plane) fracture energy

$G_{f}^{I I I}=$ mode III (out-of-plane) fracture energy

$G_{f, c}^{I I I}=$ consumed mode III (out-of-plane) fracture energy

$\mathrm{IA}=$ inverse analysis

$I P=$ integration point

SFRSCC $=$ steel fiber reinforced self compacting concrete

$\underline{T}^{c r}=$ transformation matrix from the coordinate system of the finite element to the local crack coordinate system

$f_{c}=$ compressive strength

$f_{c t}=$ tensile strength

$l_{b}=$ crack bandwidth

$l_{f}=$ steel fiber length

$n, t=$ crack local coordinate system

$O P=$ out-of-plane

$p_{1}=$ shear degradation factor

$p_{2}=$ parameter defining the mode I fracture energy available to the new crack

$s=$ sliding displacement

$w=$ opening displacement

$x_{i}=$ element local coordinate system

$\alpha_{i}=$ fracture parameters used to define the trilinear stress-strain softening diagram

$\alpha_{t h}=$ threshold angle

$\beta=$ shear retention factor

$\Delta \underline{\varepsilon}_{m f}=$ vector containing the in-plane membrane and bending strain incremental components

$\mathcal{E}^{\text {crco }}=$ elasto-cracked strain 


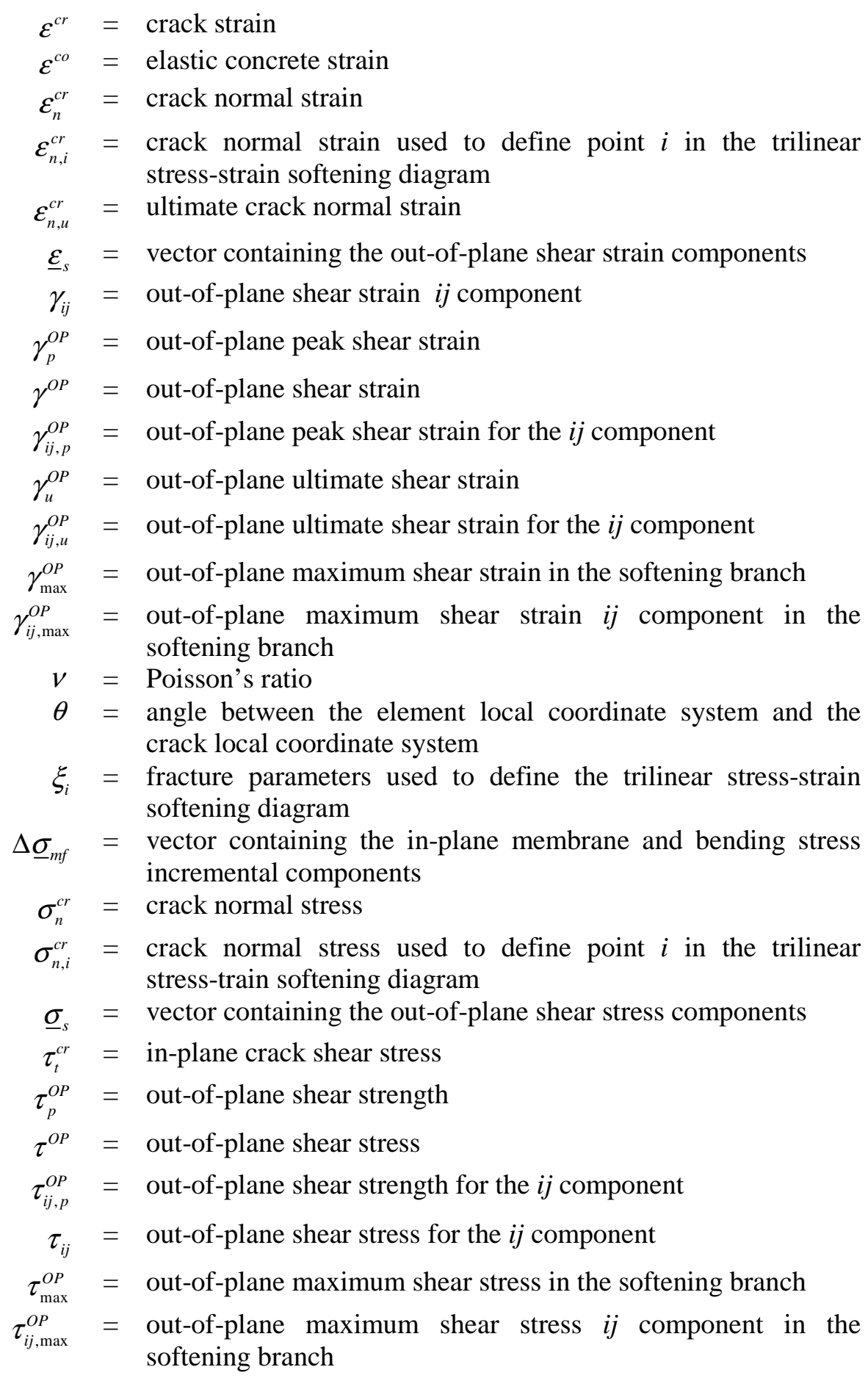




\section{TABLE CAPTIONS}

Table 1 - Composition for $1 \mathrm{~m}^{3}$ of SFRSCC including $30 \mathrm{~kg} / \mathrm{m}^{3}$ of fibers.

Table 2 - Values of the parameters of the constitutive model used in the numerical simulations of the punching test. 
Table 1 - Composition for $1 \mathrm{~m}^{3}$ of SFRSCC including $30 \mathrm{~kg} / \mathrm{m}^{3}$ of fibers

\begin{tabular}{|c|c|c|c|c|c|c|c|}
\hline \hline $\begin{array}{c}\text { Paste } \\
\text { total } \\
\text { volume } \\
(\%)\end{array}$ & $\begin{array}{c}\text { Cement } \\
\text { CEM I } \\
42.5 \mathrm{R} \\
(\mathrm{kg})\end{array}$ & $\begin{array}{c}\text { Limestone } \\
\text { filler } \\
(\mathrm{kg})\end{array}$ & $\begin{array}{c}\text { Water } \\
\left(\mathrm{dm}^{3}\right)\end{array}$ & $\begin{array}{c}\text { Super- } \\
\text { plasticizer } \\
\left(\mathrm{dm}^{3}\right)\end{array}$ & $\begin{array}{c}\text { Fine } \\
\text { sand } \\
(\mathrm{kg})\end{array}$ & $\begin{array}{c}\text { Coarse } \\
\text { sand } \\
(\mathrm{kg})\end{array}$ & $\begin{array}{c}\text { Crushed } \\
\text { aggregates } \\
(\mathrm{kg})\end{array}$ \\
\hline 0.34 & 364.28 & 312.24 & 93.67 & 6.94 & 108.59 & 723.96 & 669.28 \\
\hline \hline
\end{tabular}

$*$ Third generation based on polycarboxilates $\left(\right.$ Glenium $\left.{ }^{\circledR} 77 \mathrm{SCC}\right)$ 
Table 2 - Values of the parameters of the constitutive model used in the numerical simulations of the punching test.

\begin{tabular}{|c|c|}
\hline Poisson's ratio & $v=0.15$ \\
\hline Initial Young's modulus & $E_{c}=31000.0 \mathrm{~N} / \mathrm{mm}^{2}$ \\
\hline Compressive strength & $f_{c}=52.0 \mathrm{~N} / \mathrm{mm}^{2}$ \\
\hline $\begin{array}{l}\text { Trilinear tension softening diagram of } \\
\text { SFRSCC (used in the numerical } \\
\text { simulations of section 4.2. Parameters } \\
\text { values obtained from inverse analysis) }\end{array}$ & $\begin{array}{l}f_{c t}=3.5 \mathrm{~N} / \mathrm{mm}^{2} ; G_{f}^{I}=4.3 \mathrm{~N} / \mathrm{mm} ; \\
\xi_{1}=0.009 ; \alpha_{1}=0.5 ; \xi_{2}=0.15 ; \alpha_{2}=0.59\end{array}$ \\
\hline $\begin{array}{l}\text { Trilinear tension softening diagram of } \\
\text { SFRSCC (used in the numerical } \\
\text { simulations of section } 4.3 \text {. Parameter } \\
\text { values obtained by modifying in } \\
\pm 50 \% \text { the ones obtained from inverse } \\
\text { analysis) }\end{array}$ & $\begin{array}{l}f_{c t}=3.5 \mathrm{~N} / \mathrm{mm}^{2} ; \\
G_{f}^{I}=-50 \% \times 4.3 \mathrm{~N} / \mathrm{mm} ; \\
\xi_{1}= \pm 50 \% \times 0.009 ; \alpha_{1}= \pm 50 \% \times 0.5 ; \\
\xi_{2}= \pm 50 \% \times 0.15 ; \alpha_{2}= \pm 50 \% \times 0.59( \pm- \text { depends on the } \\
\text { numerical simulation) }\end{array}$ \\
\hline $\begin{array}{l}\text { Fracture energy (mode III) used in the } \\
\text { out-of-plane shear stress-strain } \\
\text { diagram }\end{array}$ & $\begin{array}{l}\text { from } G_{f}^{I I I}=1.0 \mathrm{~N} / \mathrm{mm} \text { to } G_{f}^{I I I}=5.0 \mathrm{~N} / \mathrm{mm} \text { (depends on } \\
\text { the numerical simulation) }\end{array}$ \\
\hline $\begin{array}{l}\text { Parameter defining the mode I fracture } \\
\text { energy available to the new crack }\end{array}$ & $p_{2}=2$ \\
\hline Shear retention factor & Exponential $\left(p_{1}=2\right)$ \\
\hline Crack bandwidth & Square root of the area of the integration point \\
\hline Threshold angle & $\alpha_{t h}=30^{\circ}$ \\
\hline
\end{tabular}

$\alpha_{1}=\sigma_{n, 2}^{c r} / \sigma_{n, 1}^{c r}, \alpha_{2}=\sigma_{n, 3}^{c r} / \sigma_{n, 1}^{c r}, \xi_{1}=\varepsilon_{n, 2}^{c r} / \varepsilon_{n, u}^{c r}, \xi_{2}=\varepsilon_{n, 3}^{c r} / \varepsilon_{n, u}^{c r}$ (see Fig. 3) 


\section{FIGURE CAPTIONS}

Fig. 1 - Concept of a lightweight steel fiber reinforced self-compacting concrete panel (dimensions in $\mathrm{mm}$ ).

Fig. 2 - Stress components, relative displacements and local coordinate system of the crack.

Fig. 3 - Trilinear stress-strain diagram to simulate the fracture mode I crack propagation of $\operatorname{SFRSCC}\left(\sigma_{n, 2}^{c r}=\alpha_{1} \sigma_{n, 1}^{c r}, \sigma_{n, 3}^{c r}=\alpha_{2} \sigma_{n, 1}^{c r}, \varepsilon_{n, 2}^{c r}=\xi_{1} \varepsilon_{n, u}^{c r}, \varepsilon_{n, 3}^{c r}=\xi_{2} \varepsilon_{n, u}^{c r}\right)$.

Fig. 4 - Diagram to simulate the relationship between the out-of-plane $(O P)$ shear stress and shear strain components.

Fig. 5 - Three-point notched beam flexural test at 7 days: (a) FEM mesh used in the numerical simulation, and (b) obtained results.

Fig. 6 - (a) Test panel module, and (b) test setup (dimensions in mm).

Fig. 7 - (a) Geometry, mesh, load and support conditions used in the numerical simulation of the punching test - Coarse Mesh (CM); (b) Properties of the layered cross section.

Fig. 8 - Relationship between load and deflection at the center of the test panel.

Fig.9 - Punching test simulation: (a) top surface cracks predicted by the numerical model (using a FEM mesh with $12 \times 12$ eight-node serendipity plane shell elements), and (b) photograph showing the cracks at the top surface of the panel, at the end of the test sequence.

Fig. 10 - Influence of $G_{f}^{I I I}$, using the in-plane coarse mesh and 3 layers in the lightweight zone, on the numerical relationship between load and deflection at the center of the test panel.

Fig. 11 - Influence of the number of layers discretizing the thickness of the panel (the number indicated is restricted to the lightweight zone of the panel).

Fig. 12 - Geometry, mesh, load and support conditions used in the numerical simulation of the punching test - Refined Mesh (RM).

Fig. 13 - Influence of the in-plane refinement on the numerical relationship between load and deflection at the center of the test panel.

Fig. 14a - Influence of $G_{f}^{I I I}$ on the numerical relationship between load and deflection at the center of the panel, when using the in-plane coarse mesh and 10 layers in the lightweight zone. 
Fig. 14b - Influence of $G_{f}^{I I I}$ on the numerical relationship between load and deflection at the center of the panel when using the in-plane refined mesh and 10 layers in the lightweight zone. Fig. 15a - Representation of the consumed out-of-plane fracture energy, $G_{f, c}^{I I I}$, when using the in-plane coarse mesh and 10 layers in the lightweight zone, for a deflection of $3.5 \mathrm{~mm}$.

Fig. 15b - Representation of the consumed out-of-plane fracture energy, $G_{f, c}^{I I I}$, when using the in-plane refined mesh and 10 layers in the lightweight zone, for a deflection of $3.5 \mathrm{~mm}$.

Fig. 16 - Influence of the $\xi_{1}$ parameter: (a) trilinear softening diagrams and (b) relationship between load and deflection at the center of the test panel.

Fig. 17 - Influence of the $\alpha_{1}$ parameter: (a) trilinear softening diagrams and (b) relationship between load and deflection at the center of the test panel.

Fig. 18 - Influence of the $\xi_{2}$ parameter: (a) trilinear softening diagrams and (b) relationship between load and deflection at the center of the test panel.

Fig. 19 - Influence of the $\alpha_{2}$ parameter: (a) trilinear softening diagrams and (b) relationship between load and deflection at the center of the test panel.

Fig. 20 - Influence of $G_{f}^{I}$ : (a) trilinear softening diagrams and (b) relationship between load and deflection at the center of the test panel. 


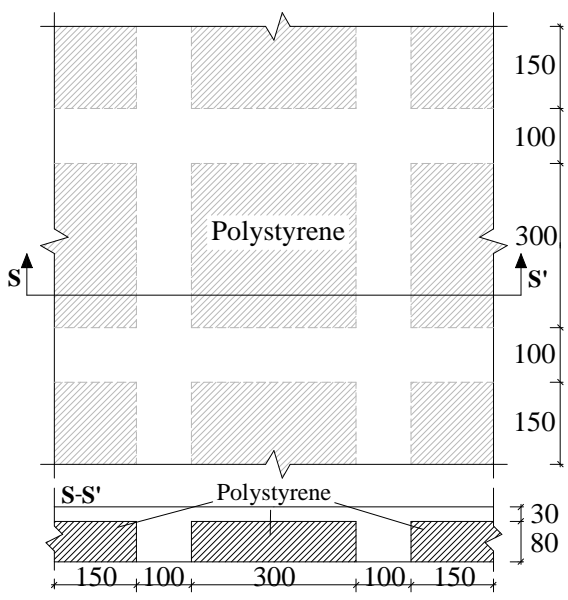

Fig. 1 - Concept of a lightweight steel fiber reinforced self-compacting concrete panel (dimensions in $\mathrm{mm}$ ). 


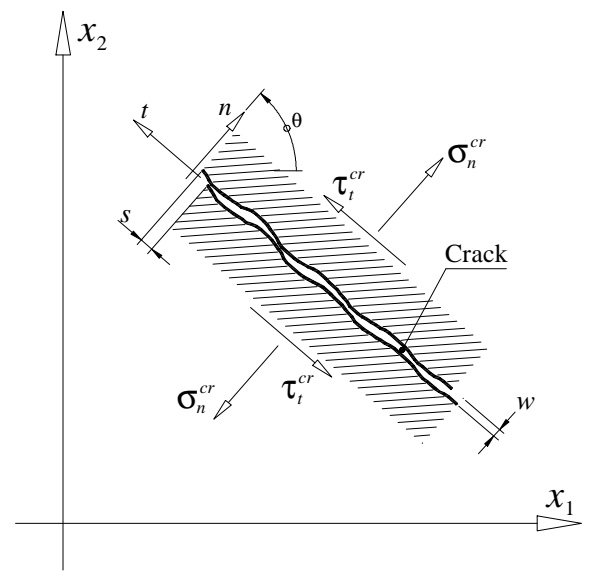

Fig. 2 - Stress components, relative displacements and local coordinate system of the crack. 


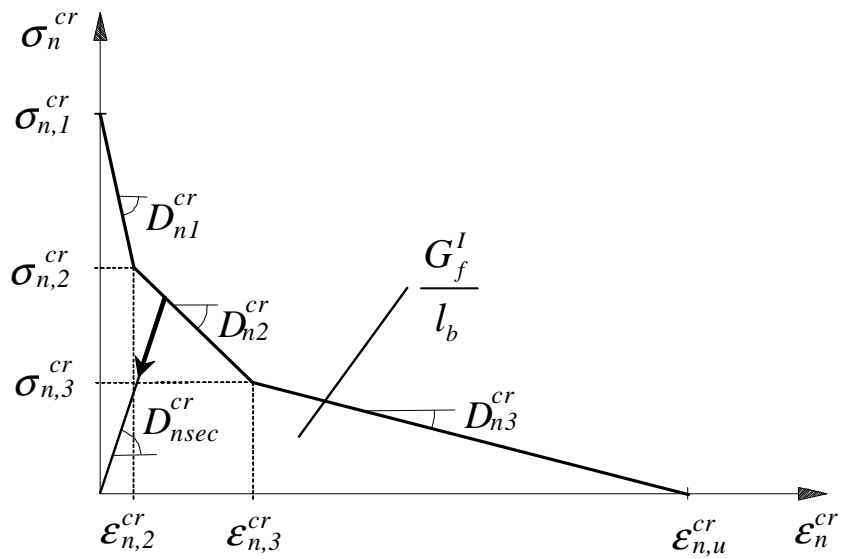

Fig. 3 - Trilinear stress-strain diagram to simulate the fracture mode I crack propagation of SFRSCC ( $\sigma_{n, 2}^{c r}=\alpha_{1} \sigma_{n, 1}^{c r}$, $\left.\sigma_{n, 3}^{c r}=\alpha_{2} \sigma_{n, l}^{c r}, \varepsilon_{n, 2}^{c r}=\xi_{1} \varepsilon_{n, u}^{c r}, \varepsilon_{n, 3}^{c r}=\xi_{2} \varepsilon_{n, u}^{c r}\right)$. 


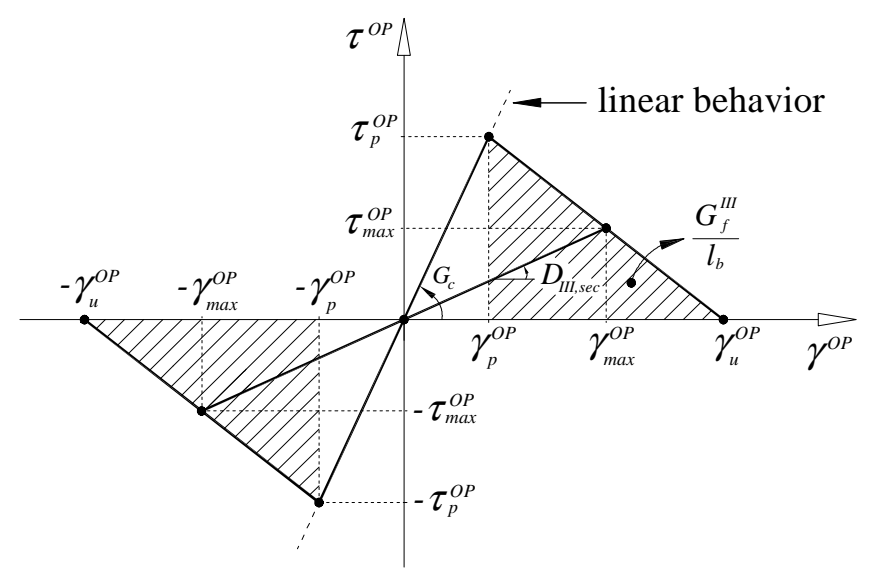

Fig. 4 - Diagram to simulate the relationship between the out-of-plane $(O P)$ shear stress and shear strain components. 
(a)

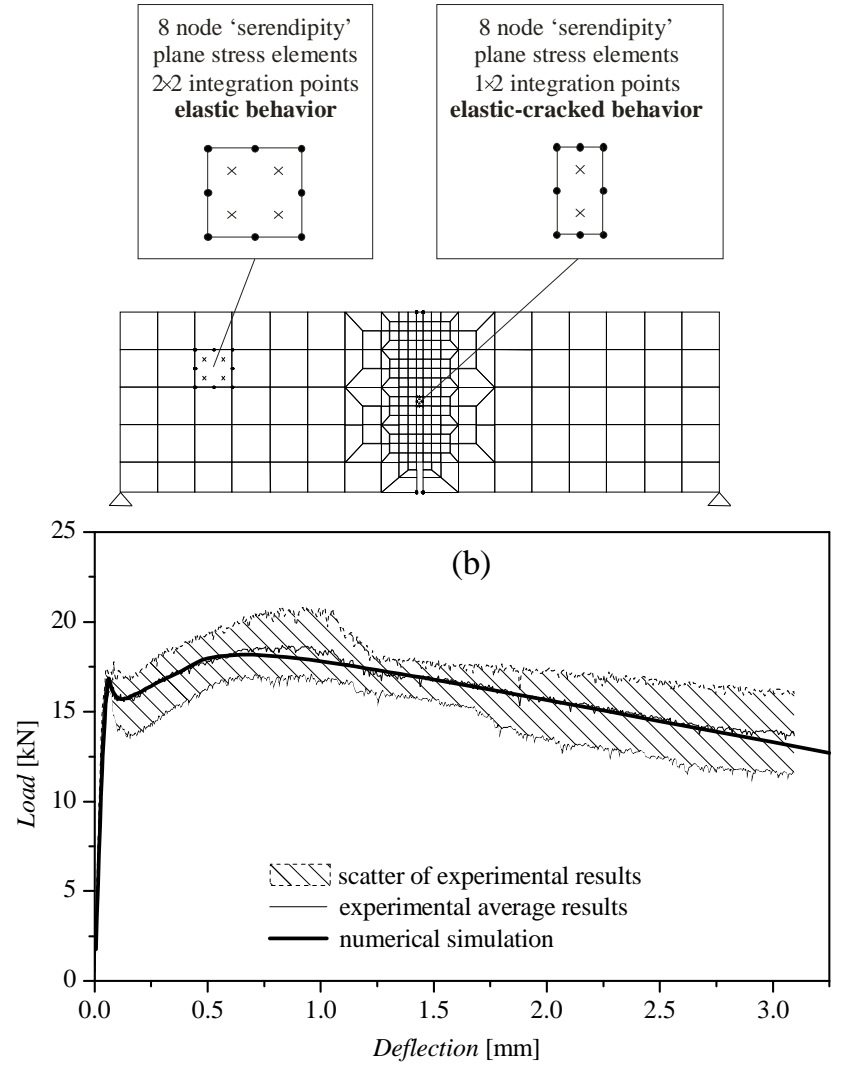

Fig. 5 - Three-point notched beam flexural test at 7 days: (a) FEM mesh used in the numerical simulation, and (b) obtained results. 


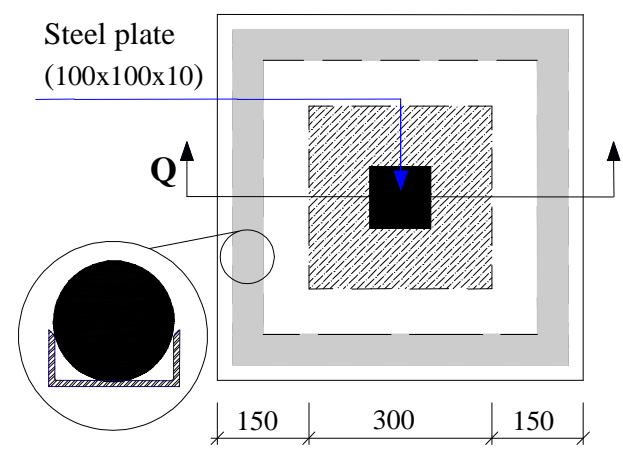

(a)

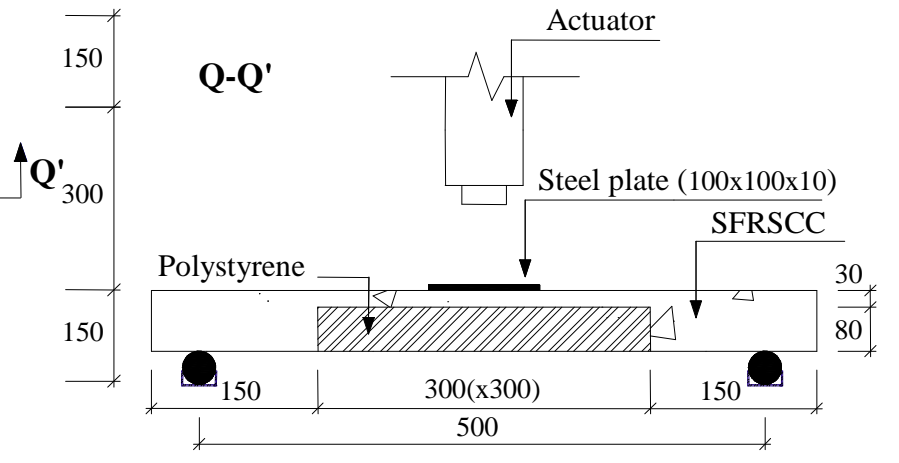

(b)

Fig. 6 - (a) Test panel module, and (b) test setup (dimensions in mm). 


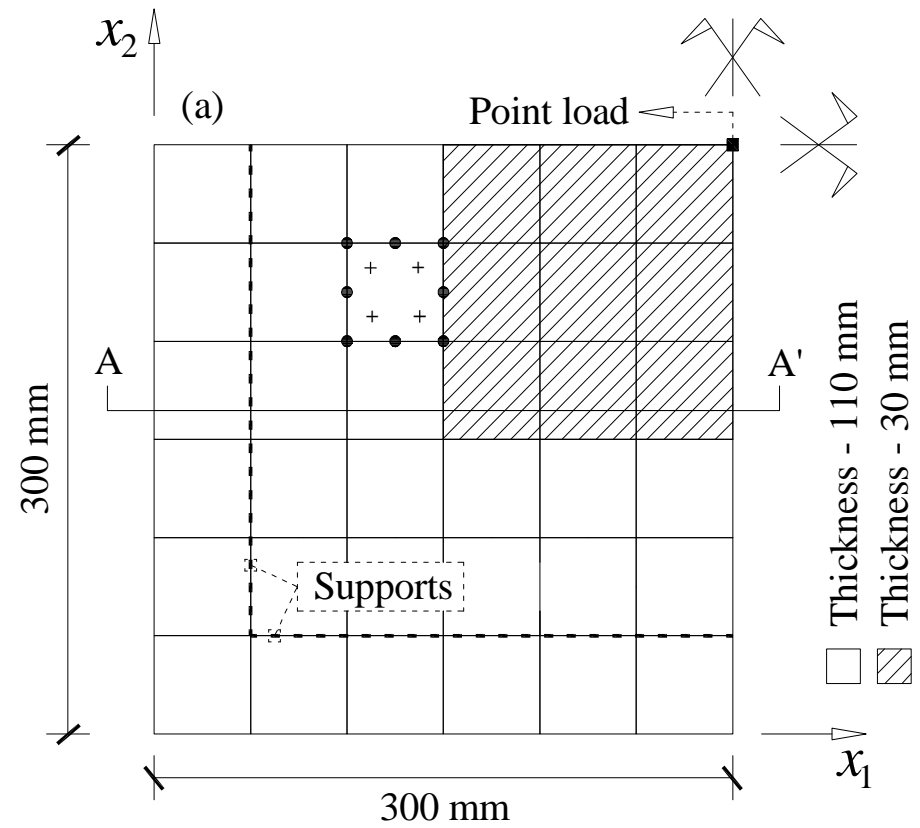

(b) Cross section: A-A'

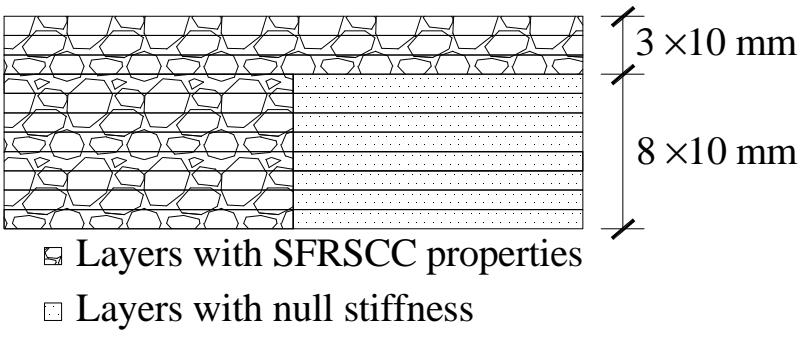

Fig. 7 - (a) Geometry, mesh, load and support conditions used in the numerical simulation of the punching test - Coarse Mesh (CM); (b) Properties of the layered cross section. 


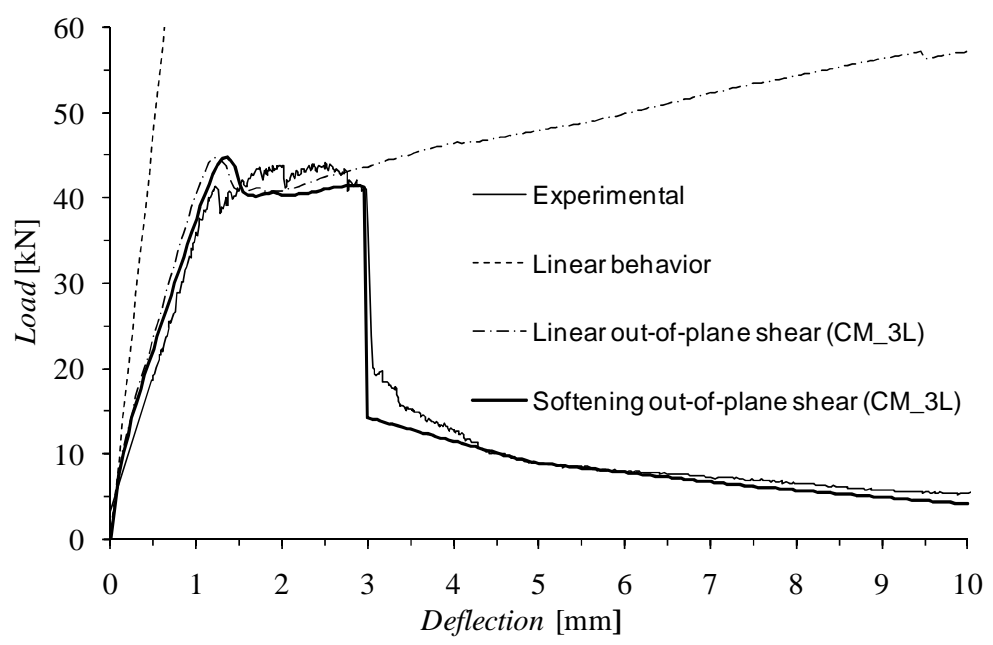

Fig. 8 - Relationship between load and deflection at the center of the test panel. 

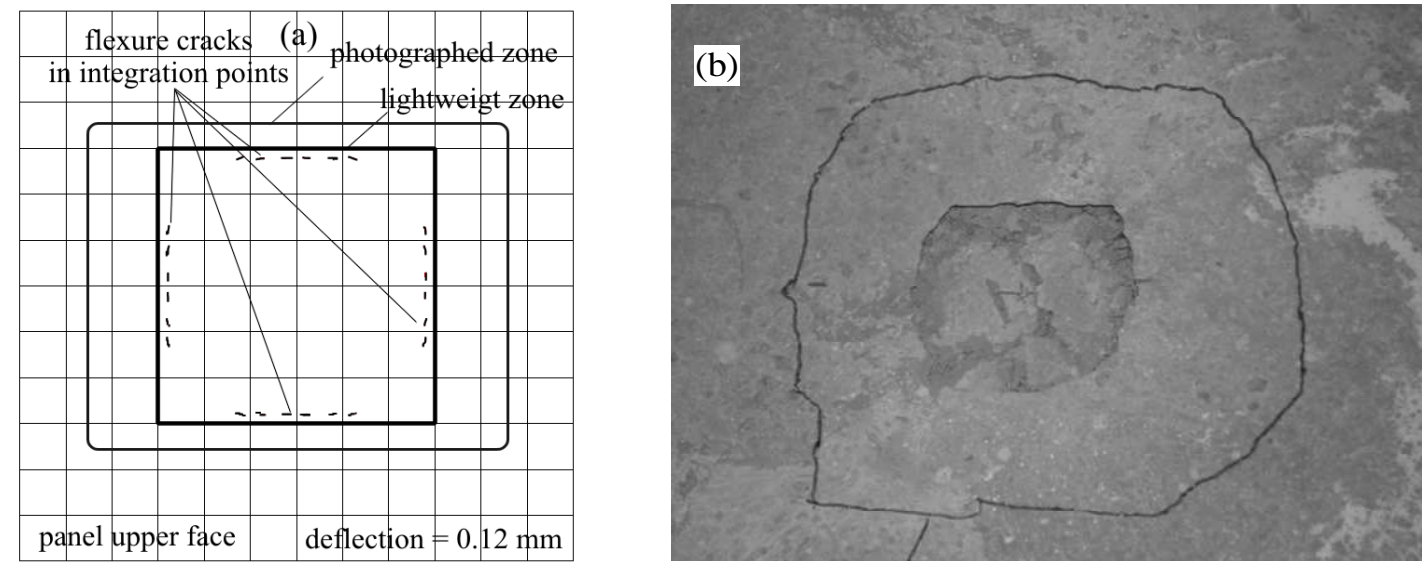

Fig.9 - Punching test simulation: (a) top surface cracks predicted by the numerical model (using a FEM mesh with $12 \times 12$ eight-node serendipity plane shell elements), and (b) photograph showing the cracks at the top surface of the panel, at the end of the test sequence. 


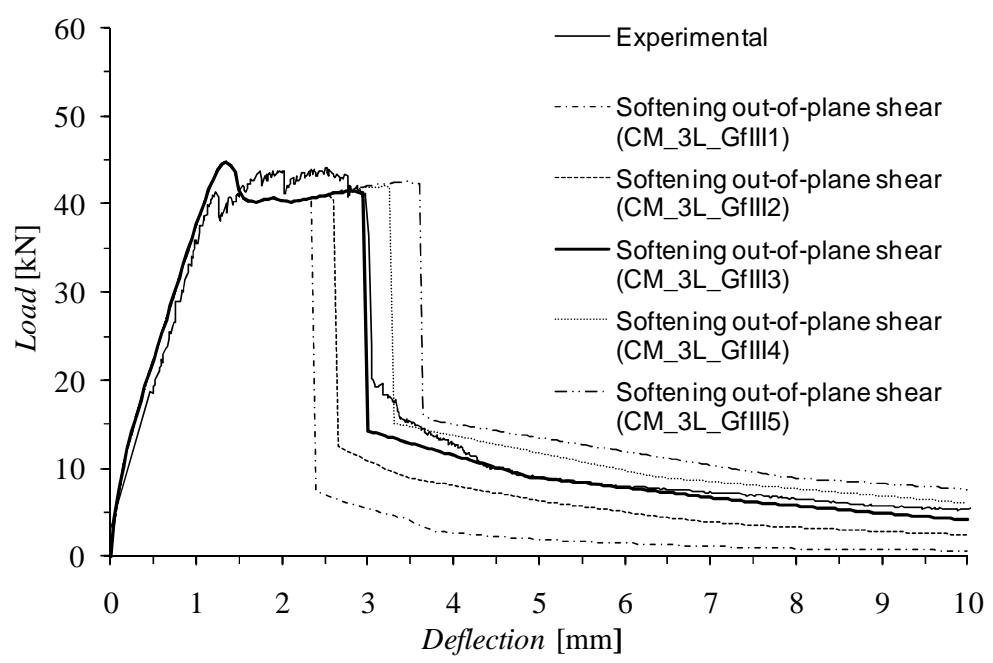

Fig. 10 - Influence of $G_{f}^{I I I}$, using the in-plane coarse mesh and 3 layers in the lightweight zone, on the numerical relationship between load and deflection at the center of the test panel. 


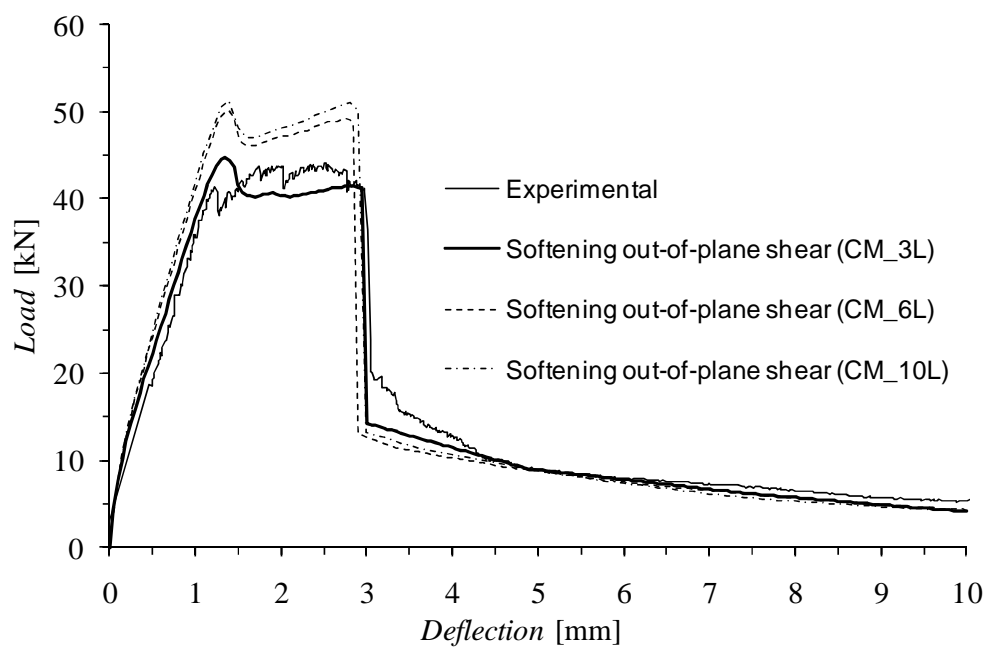

Fig. 11 - Influence of the number of layers discretizing the thickness of the panel (the number indicated is restricted to the lightweight zone of the panel). 


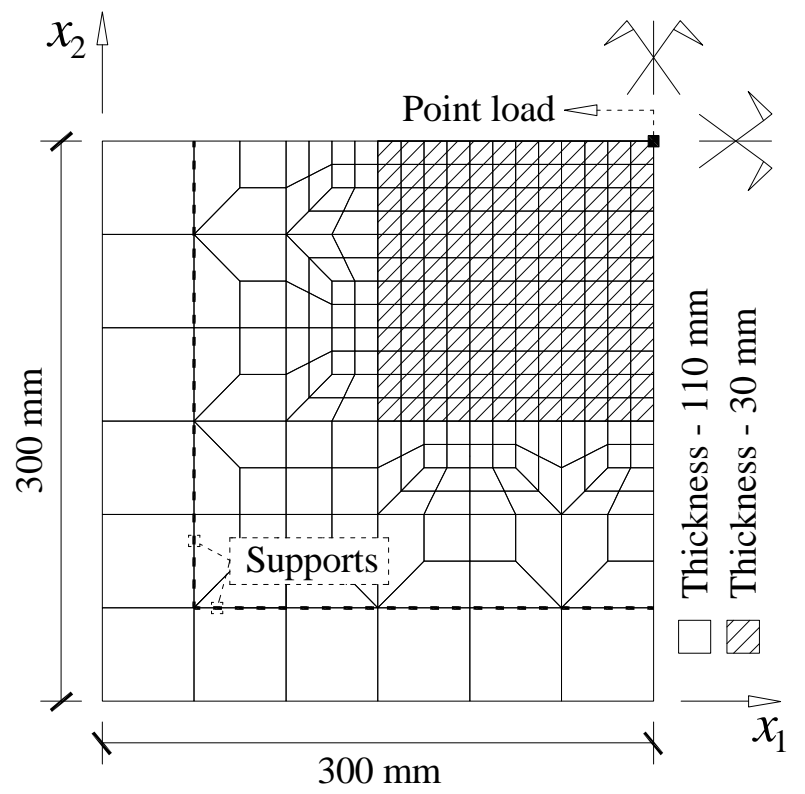

Fig. 12 - Geometry, mesh, load and support conditions used in the numerical simulation of the punching test - Refined Mesh (RM). 


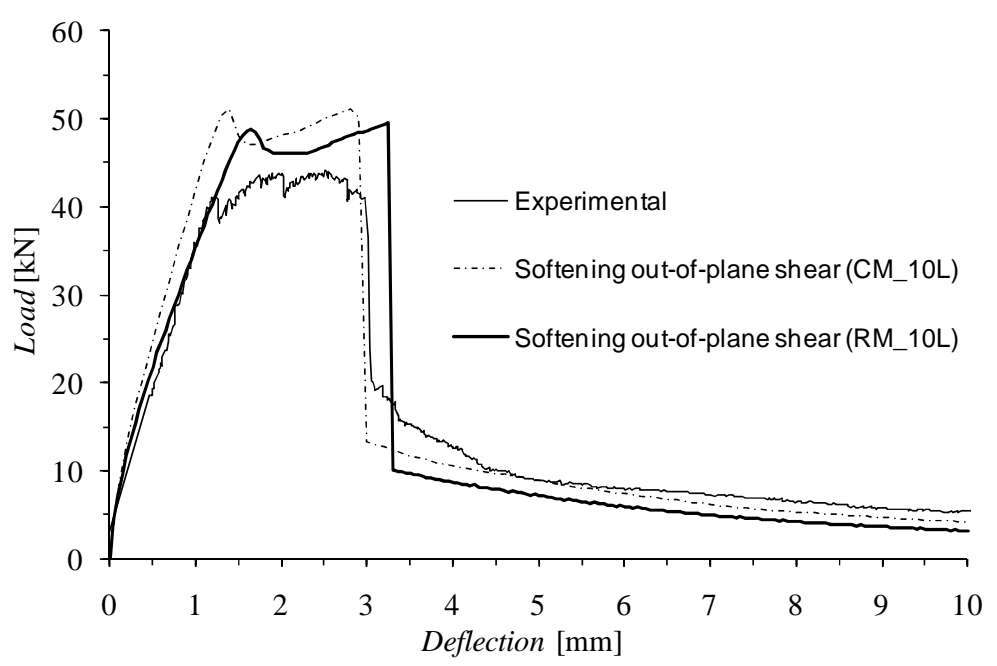

Fig. 13 - Influence of the in-plane refinement on the numerical relationship between load and deflection at the center of the test panel. 


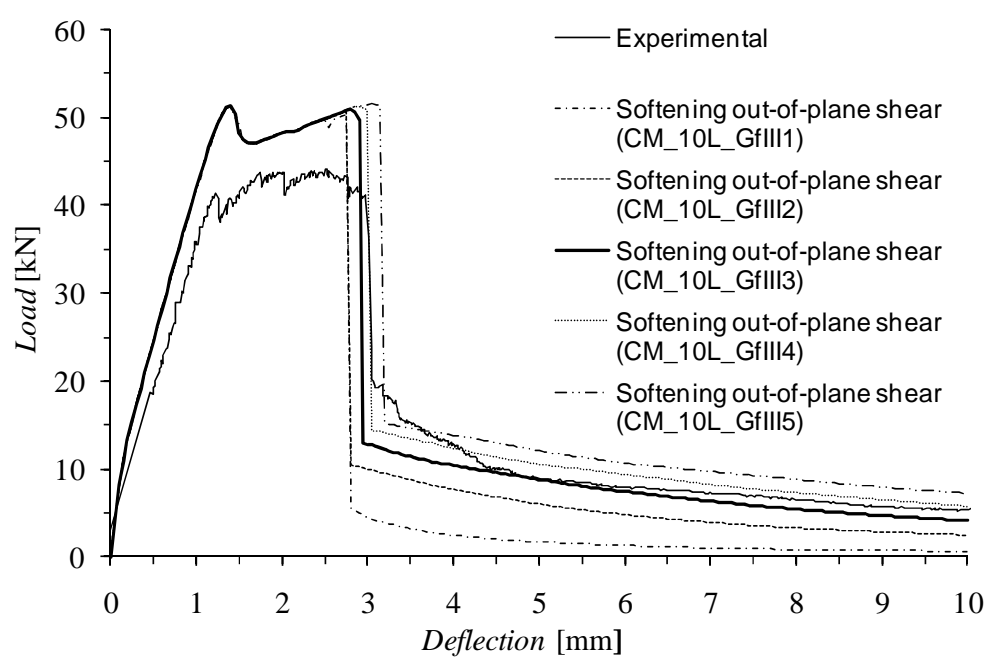

Fig. 14a- Influence of $G_{f}^{I I I}$ on the numerical relationship between load and deflection at the center of the panel, when using the in-plane coarse mesh and 10 layers in the lightweight zone.

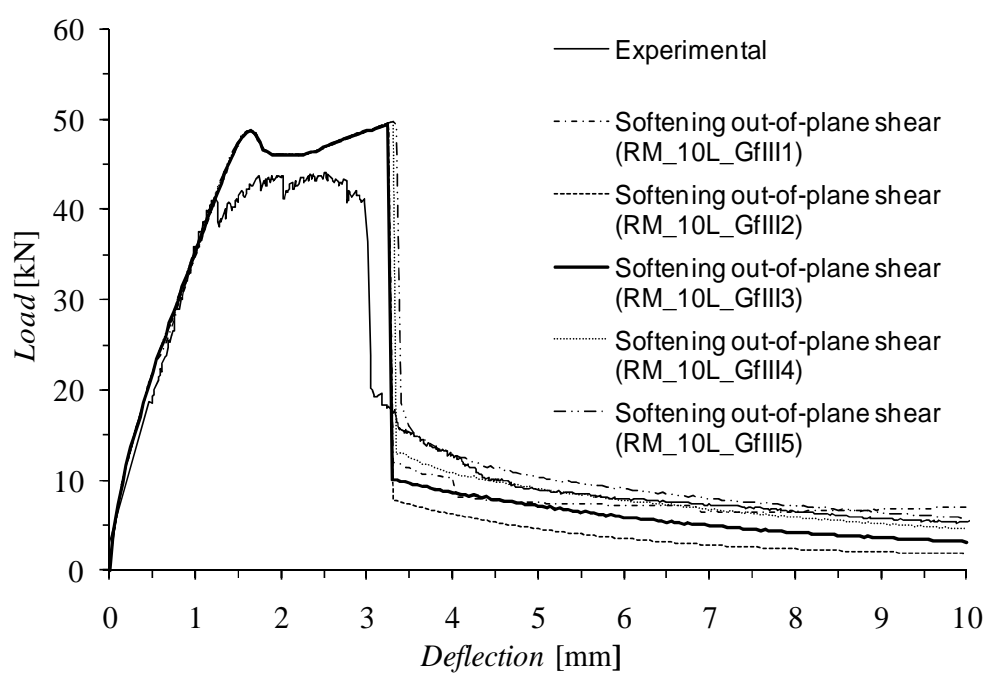

Fig. 14b- Influence of $G_{f}^{I I I}$ on the numerical relationship between load and deflection at the center of the panel when using the in-plane refined mesh and 10 layers in the lightweight zone. 


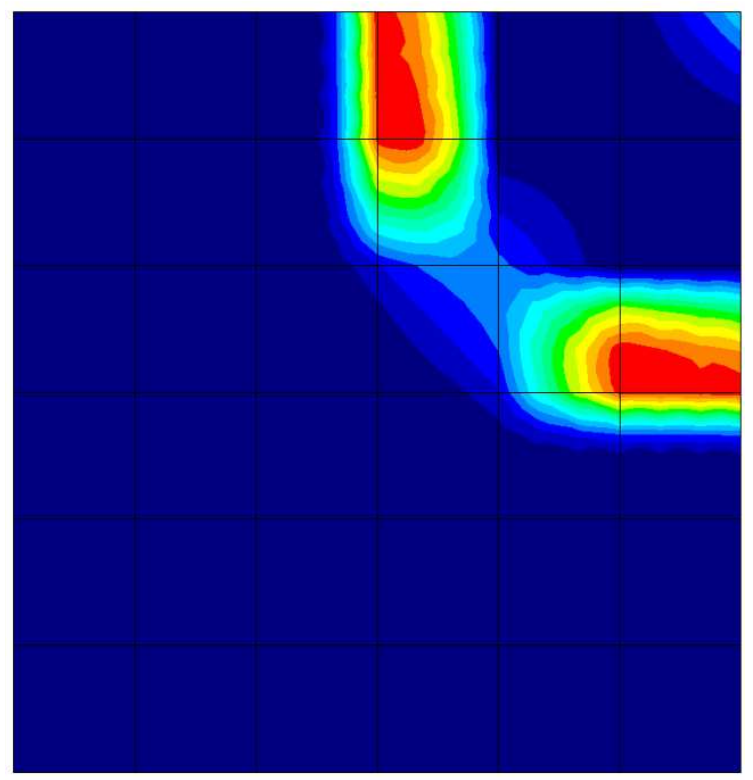

Fig. 15a- Representation of the consumed out-of-plane fracture energy, $G_{f, c}^{I I I}$, when using the in-plane coarse mesh and 10 layers in the lightweight zone, for a deflection of $3.5 \mathrm{~mm}$.

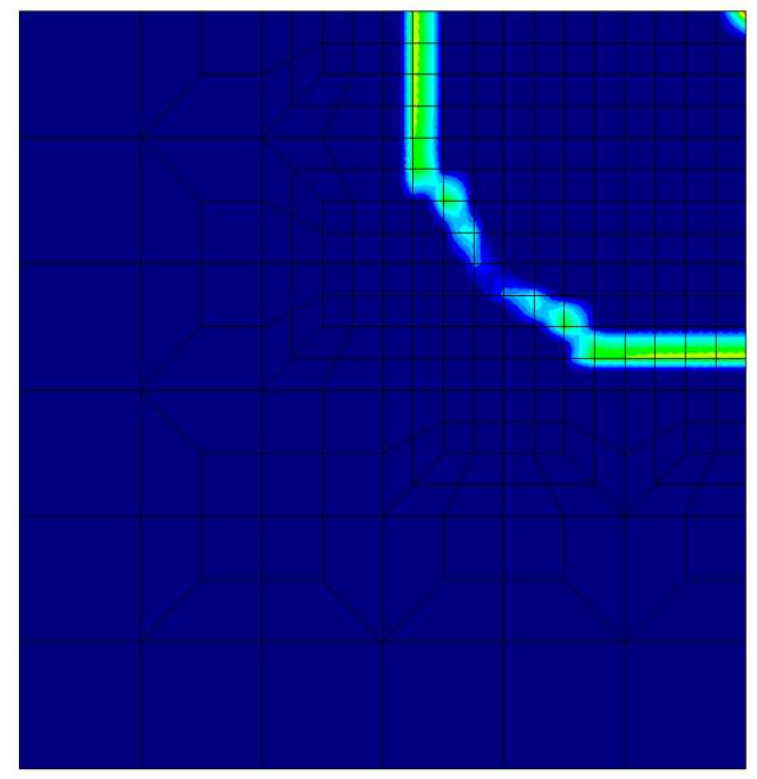

Fig. 15b - Representation of the consumed out-of-plane fracture energy, $G_{f, c}^{I I I}$, when using the in-plane refined mesh and 10 layers in the lightweight zone, for a deflection of $3.5 \mathrm{~mm}$. 


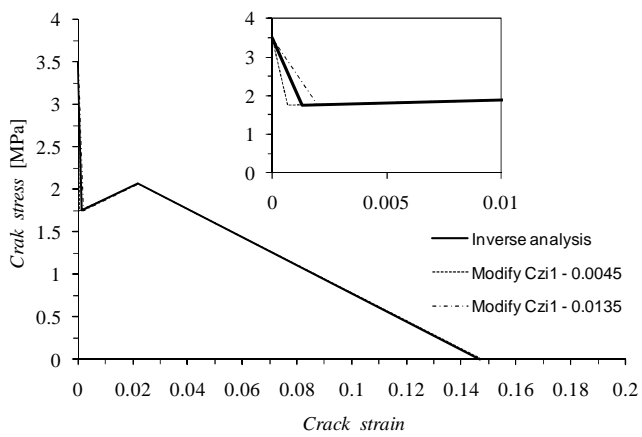

(a)

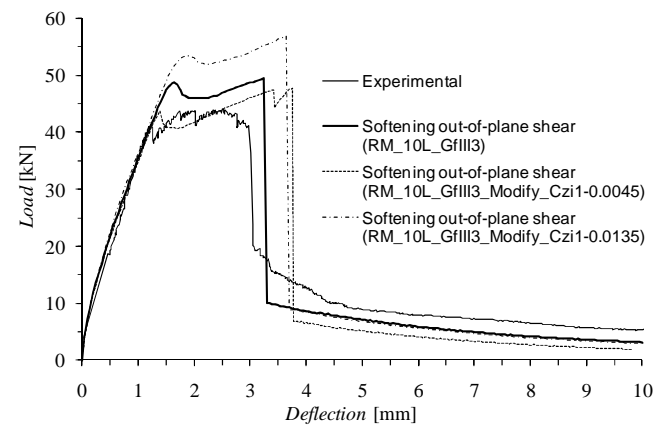

(b)

Fig. 16 - Influence of the $\xi_{1}$ parameter: (a) trilinear softening diagrams and (b) relationship between load and deflection at the center of the test panel. 


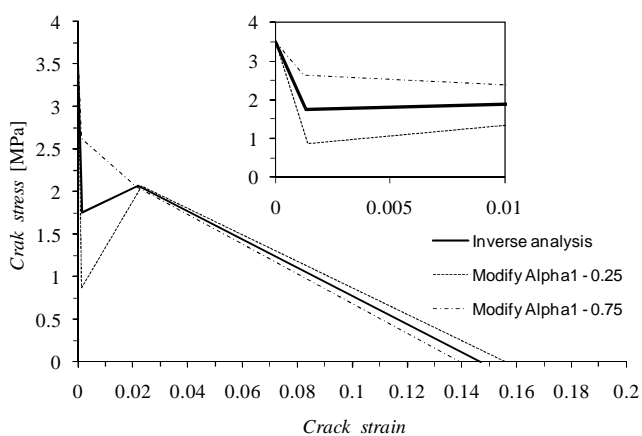

(a)

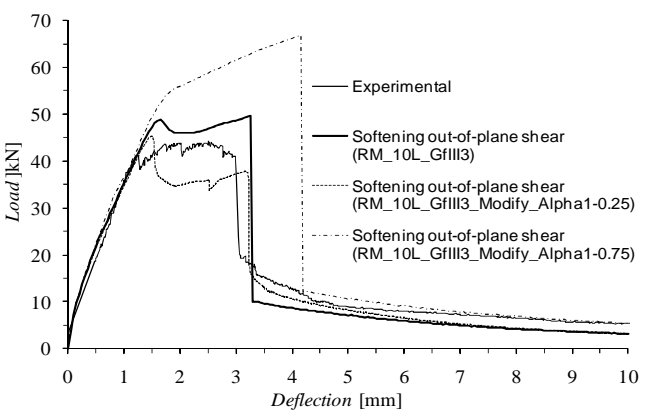

(b)

Fig. 17 - Influence of the $\alpha_{1}$ parameter: (a) trilinear softening diagrams and (b) relationship between load and deflection at the center of the test panel. 


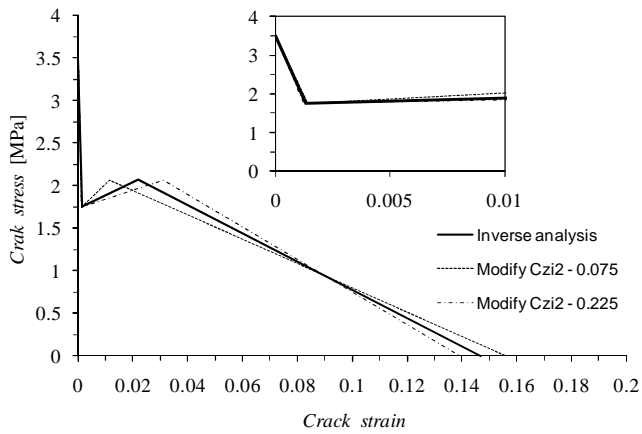

(a)

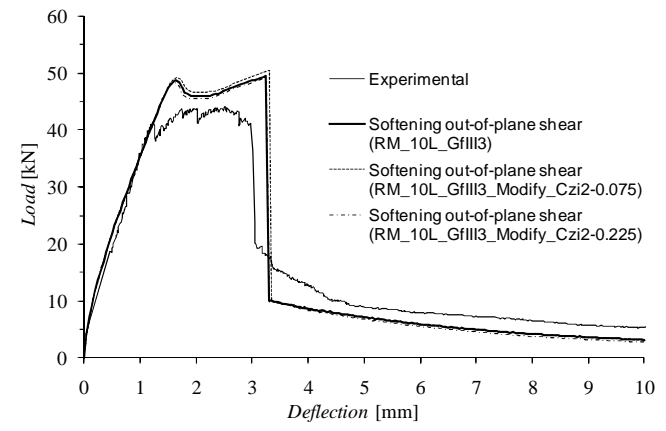

(b)

Fig. 18 - Influence of the $\xi_{2}$ parameter: (a) trilinear softening diagrams and (b) relationship between load and deflection at the center of the test panel. 


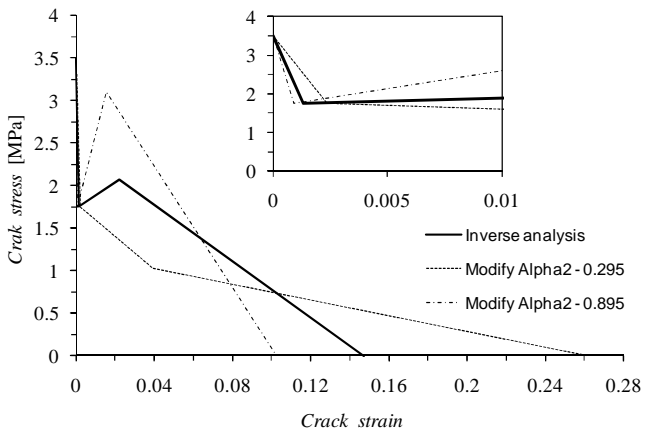

(a)

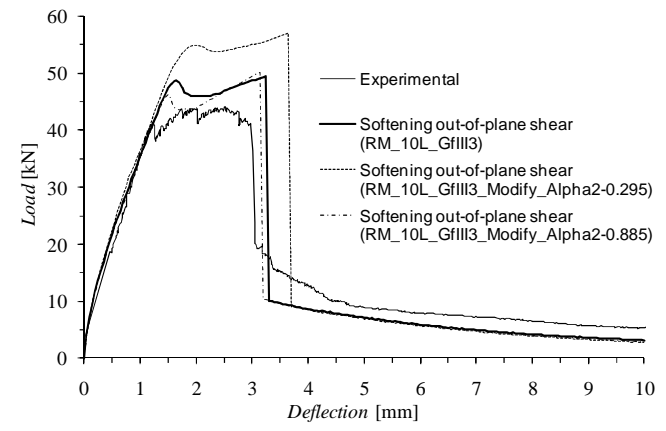

(b)

Fig. 19 - Influence of the $\alpha_{2}$ parameter: (a) trilinear softening diagrams and (b) relationship between load and deflection at the center of the test panel. 


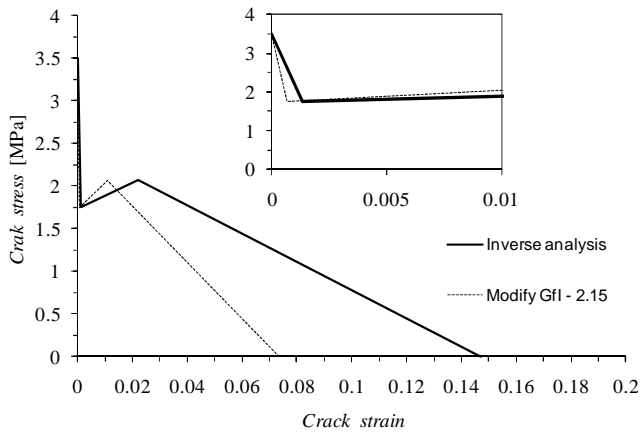

(a)

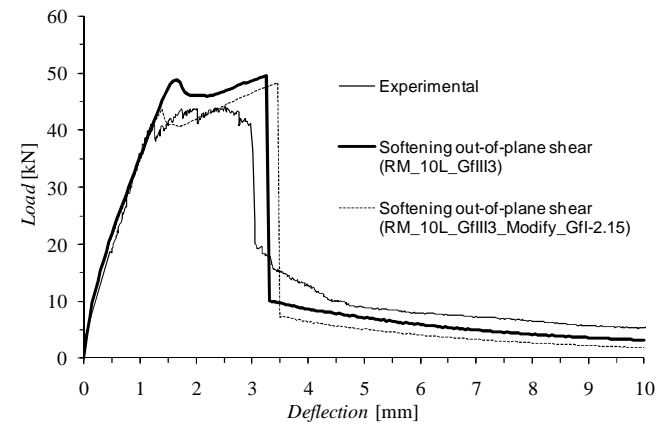

(b)

Fig. 20 - Influence of $G_{f}^{I}$ : (a) trilinear softening diagrams and (b) relationship between load and deflection at the center of the test panel. 